\title{
O discurso sem palavra Uma outra dimensão da linguagem
}

\author{
Speech without speech \\ Another dimension of language
}

DOI: $10.46814 / \mathrm{lajdv} 2 \mathrm{n} 6-006$

Recebimento dos originais: 01/09/2020

Aceitação para publicação: 30/10/2020

\section{Fabiano de Abreu Rodrigues}

Doutor e Mestre em Psicologia da Saúde pela Université Libre des Sciences de l'Homme de Paris Doutor e Mestre em Ciências da Saúde com ênfase em Psicologia e Neurociência pela Emil Brunner

World University;

Mestre em Psicanálise Freudiana e Lacaniana pelo Instituto e Faculdade Gaio Especialização em Propriedades Elétricas dos Neurônios em Harvard Especialização em Nutrição Clínica pela TranningHouse

Neurocientista, Neuropsicólogo, Psicólogo, Psicanalista, Jornalista e Filósofo integrante da SPN Sociedade Portuguesa de Neurociências - 814, da SBNEC - Sociedade Brasileira de Neurociências e Comportamento - 6028488 e da FENS - Federation of European Neuroscience Societies - PT30079.

Endereço: Rua Costinha S/N - Bairros - Castelo de Paiva - Aveiro - Portugal

E-mail: deabreu.fabiano@gmail.com

\section{RESUMO}

GUALBERTO, Pablo Henrique Silva de Araujo. Psicanálise existencial: Uma proposta sartriana de assumir-se enquanto sujeito. 2020. Número total de folhas. Trabalho de Conclusão de Curso de Psicanálise Clínica - Instituto GAIO Ensino Superior. Belo Horizonte, 2020.

Jean-Paul Sartre, em determinado momento, dá a sua visão e reformula a teoria psicanalítica desenvolvida por Sigmund Freud, colocando o sujeito em uma posição mais ativa e não empírica; desta maneira, Sartre nos diz que o homem é aquilo que faz com o que fazem dele, por ele e/ou com ele, afastando-se, então, da proposta freudiana do inconsciente.

Palavras-chave: Psicanálise, Jean-Paul Sartre, Sigmund Freud, Existencialismo, Homem.

\begin{abstract}
GUALBERTO, Pablo Henrique Silva de Araujo. Existential psychoanalysis: A Sartrian proposal to assume yourself as a subject. 2020. Total number of sheets. Conclusion of Clinical Psychoanalysis Course - Instituto GAIO Ensino Superior. Belo Horizonte, 2020.

Jean-Paul Sartre, at a given moment, gives his vision and reformulates the psychoanalytic theory developed by Sigmund Freud, placing the subject in a more active and not an empirical position; in this way, Sartre tells us that man is what he does with what he does, for him and / or with him, moving away, then, from the Freudian proposal of the unconscious.
\end{abstract}

Keywords: Psychoanalysis, Jean-Paul Sartre, Sigmund Freud, Existentialism, Man. 


\section{INTRODUÇÃO}

Fundada por Sigmund Freud entre 1885 e 1939 a psicanálise constitui-se como uma prática terapêutica que visa a investigação de conteúdos recalcados na mente humana bem como as fases de desenvolvimento psíquico do indivíduo e está em contínuo desenvolvimento por todos os psicanalistas e estudantes de psicanálise desde então.

Neste presente trabalho busco apresentar a proposta de Jean-Paul Sartre sobre uma linha psicanalítica não empírica que visa colocar o sujeito em uma posição mais ativa em relação a sua própria vida considerando também as interferências contingentes da sociedade (ainda que esta não seja uma totalidade na constituição do sujeito).

$\mathrm{Na}$ visão existencialista sartriana o homem primeiro existe, se descobre enquanto ser, reconhece a sua existência no mundo e apenas depois de todo esse processo se define enquanto indivíduo assumindo, então, sua total responsabilidade por sua existência uma vez que por ter escolhido sua formação escolhe, também, todos os homens.

Desta maneira o objeto de estudo deste presente trabalho é mostrar onde existe semelhança e distanciamento entre a psicanálise freudiana e a psicanálise existencial de Sartre.

Para que haja uma melhor compreensão, o trabalho foi apresentado em três momentos, sendo eles: "Do existencialismo", onde haverá explicações acerca da temática, "Da psicanálise”, para que possamos tomar conhecimento embasados acerca da teoria freudiana e "Da psicanálise existencialista", onde poderemos averiguar as propostas, semelhanças e distanciamento entre a práticas.

\subsection{DO EXISTENCIALISMO}

$\mathrm{O}$ existencialismo começou a surgir em meados do século XX e com o passar do tempo muitos pensadores contribuíram com o seu trabalho para o desenvolvimento do que conhecemos hoje por existencialismo.

Sören Kierkegaard, conhecido como "O pai do existencialismo", foi um filósofo dinamarquês que baseou sua teoria existencial pautando-se na existência de Deus defendendo, então, a irredutibilidade do homem e que este tinha a sua essência diretamente ligada à divindade sendo, desta maneira, uma filosofia de cunho metafísico.

Paralelo ao pensamento existencialista kierkegaardiano tivemos uma influência que chamamos de fenomenológica que trata-se de reconhecer fenômenos que acontecem na mente humana e, também, no mundo como um todo. A fenomenologia, em determinado momento divide, então, o existencialismo em duas linhas de pensamento: o existencialismo cristão (defendido por 
Kierkegaard) e o existencialismo ateu, que defende a negação da natureza do homem. Estas se diferem pelo simples fato de que Kierkergaard defendia que a natureza do homem estava ligada intimamente à concepção de Deus.

Além de Kierkergaard, tivemos grandes pensadores e pensadoras defensores do existencialismo, seja cristão ou ateu, tais como: Jean-Paul Sartre, Merleau-Ponty, Albert Camus, Karl Jaspers, Martin Heidegger, Fiódor Dostoiévski, Hannah Arendt, entre outros.

\subsection{EXISTENCIALISMO SARTRIANO}

Dando, então, atenção apenas a um destes pensadores citados anteriormente, Sartre era existencialista que se distanciava da ideia do então chamado de existencialismo cristão, que colocava que a natureza do homem está diretamente ligada a Deus. Em seu livro "O existencialismo é um humanismo", nos diz que

"O homem, tal como o concebe existencialista, se não é definível, é porque primeiramente não é nada. Só depois será alguma coisa tal como a si próprio se fizer. Assim, não há natureza humana, visto que não há Deus para a conceber." (SARTRE, Jean-Paul. O Existencialismo é um Humanismo. São Paulo: Abril Cultural, 1973, p. 12).

Desta maneira, entende-se que a liberdade defendida por Sartre está em assumir-se enquanto indivíduo aceitando assim, de maneira mais ativa e efetiva, a sua existência, que é constituída, sobretudo, de acordo com sua vontade e assumindo sua responsabilidade diante de suas escolhas, sejam estas assertivas ou não.

O pensamento sartriano teve em suas raízes teorias e estudos de importantes filósofos que antecedem seus trabalhos e formatam seu modo de pensar e apresentar o existencialismo, tais como, Kierkegaard (como citado anteriormente), Friederich Nietzsche, Martin Heidegger e Edmund Hursserl. Assim sendo, podemos perceber que enraizado em sua estrutura existencial, Sartre nos trás de seus antecedentes um distanciamento do existencialismo cristão (baseando-se no existencialismo de Kierkegaard), a vida em sua estrutura fisiológica, afastando-se assim, da filosofia tradicional metafísica (de Friederich Nietzsche), a fenomenologia ( de Edmund Hursserl) e no pensamento acerca do Ser (de Martin Heidegger).

\section{DA PSICANÁLISE}

Para entender o conceito de psicanálise existencial se faz necessário o entendimento do que é a psicanálise, onde e como surgiu esta linha de conhecimento e como é aplicada. 
Sigismund (Sigmund) Schlomo Freud (1856 - 1939), criador da psicanálise, na adolescência

“[...]começou a escrever um diário dos seus sonhos. Entrou na Faculdade de Medicina da Universidade de Viena em 1873 (aos 17 anos de idade).” (GAIO, Instituto. Introdução à psicanálise. Formação em Psicanálise Clínica.).

Freud estudou com Jean-Martin Charcot (médico e cientista francês), em Paris, utilizando-se do método catártico através da hipnose em pacientes histéricas e, também, com Josef Breuer (médico e fisiologista austríaco. Seu trabalho e ideias foram a base para o desenvolvimento dos estudos e desenvolvimento da psicanálise, de Freud.). Em determinado momento Freud nota, então, que

“[...] há uma outra lógica operando na estrutura psíquica humana, além da consciência: o inconsciente. [...] além da consciência outra lógica operava no homem, em que alguns conteúdos permaneciam não revelados ao sujeito: o inconsciente. A Psicanálise considerava tudo de ordem mental como sendo consciente ou inconsciente. $\mathrm{O}$ inconsciente é ambivalente, pois o tempo não é linear e contrários coexistem, como o não e o sim.” (CARLONI, Paola. A história e a constituição da Psicanálise: introdução aos principais conceitos freudianos para entender a subjetividade humana, 2011, p. 3).

\subsection{PRIMEIRA TÓPICA}

A partir deste momento Freud começa a desenvolver sua teoria que é conhecida por nós por primeira tópica que divide o aparelho psíquico em três partes, sendo elas, o inconsciente, que é a fonte energética do sujeito e, para a psicanálise, a maior parte da mente humana, o pré-consciente, que consiste em uma parte da instancia psíquica que pode, de alguma forma, se manifestar no consciente, e o consciente, que é uma

"[...] pequena parte da mente, inclui tudo do que estamos cientes num dado momento. Embora Freud estivesse interessado nos mecanismos da consciência, seu interesse era muito maior com relação às áreas da consciência menos expostas e exploradas, que ele denominava pré-consciente e inconsciente. (FADIMAN, J.,Frager, R.Teorias da Personalidade. Harbra. 1980, Cap. 1)

\subsection{SEGUNDA TÓPICA}

Ao revisar seu trabalho desenvolvido na primeira tópica, Freud percebe que seu modelo possuía alguns pontos que poderiam passar por melhorias e propôs, desta forma, a segunda tópica, que teria o intuito não de excluir a primeira e inviabilizá-la pois esta, a primeira tópica, foi necessária para o desenvolvimento da segunda, mas sim, rever pontos que poderiam ser melhorados e

“[...] Até então, Freud achava que o ego estava totalmente situado no consciente e no pré-consciente, afinal no inconsciente estariam apenas aquelas representações mentais que o ego teria recalcado. Em outras palavras, naquele momento Freud considerava que o conflito psíquico que levaria ao adoecimento psicológico seria travado entre um ego consciente que não quer admitir determinados pensamentos e o conjunto 
inconsciente desses pensamentos recalcados, ou seja, um conflito ego versus inconsciente. (GAIO, Instituto. Teoria Psicanalítica de Sigmund Freud I. Formação em Psicanálise Clínica).

Assim sendo, a segunda tópica, semelhante à primeira se divide em três instâncias. No entanto estas, as da segunda tópica, se dividem em ID, Ego e Superego.

O Ego é a nossa parte comandada pelo princípio de realidade, logo, é aquela que transparecemos às pessoas ao nosso redor e tenta realizar os desejos vindo do ID de maneira mais adequada à realidade. O ID é movido pelo princípio de prazer e acompanha o indivíduo desde o seu nascimento, no entanto, a maior parte dos desejos são reprimidos. Já o superego é a parte do aparelho psíquico que estrutura o indivíduo limitando-o através de normas e padrões.

\subsection{DEFINIÇÃO DE PSICANÁLISE}

Após a compreensão da primeira e da segunda tópica de Freud se torna mais clara a compreensão do que de fato vem a ser a psicanálise.

Entende-se, então, que é uma análise investigativa do aparelho psíquico do sujeito em busca da cura ou a melhoria de sua saúde mental através de um método que conhecemos hoje por associação livre. Concordando, desta maneira, que para Freud psicanálise é

\footnotetext{
"1. Um procedimento para a investigação de processos mentais que de outra forma são praticamente inacessíveis. 2. Um método baseado nessa investigação para o tratamento de transtornos neuróticos. 3. Uma série de concepções psicológicas adquiridas por esse meio e que se somam umas às outras para formar progressivamente uma nova disciplina científica." (FREUD, Sigmund. Dois Verbetes de Enciclopédia. In: Edição Standard Brasileira das Obras Psicológicas Completas. Rio de Janeiro: Imago; 1976)
}

\section{PSICANÁliSe EXISTENCIAL: UMA FUSÃo ENTRE A PSICANÁliSE E O EXISTENCIALISMO}

Compreender a subjetividade é entender todo o desenvolvimento da subjetivação, identificar a subjetividade e a liberdade do sujeito para que ele não se torne "coisa" ou "objeto", como diz Sartre, analisar o processo da personalização do sujeito no mundo inserido, dentro da sua liberdade, para essa personalização o transeunte é protagonista da sua ação, tensão e modo de agir, essa é uma resposta do sujeito perante ao mundo que oferece a liberdade de escolha.

A pessoa é colocada perante ao mundo que oferece a liberdade na qual suas escolhas tornará seu destino, trazendo consigo o significado e o desenvolvimento de valores existencialistas, a representação dos fatos faz com que o homem não seja inessencial . O indivíduo é uma síntese no universo que busca para si o desejo de ser numa singularidade concreta e completa. 
O existencialismo sartriano e a história do homem faz com que a psicanálise existencial seja instrumento, disciplina auxiliar, no processo do desenvolvimento da autonomia do indivíduo buscando entender em praxis análise de maneira freudiana a conexão do consciente, pré-consciente e inconsciente, mesmo antes de Jean Paul Sartre apresentar sua visão existencialista diferentemente proposta por Kierkegaard. Como indivíduos sempre em progresso, somos seres subjetivos e objetivos como já dizia Freud, na qual anseiamos e procuramos satisfazer nossos desejos no mundo inserido, ao mesmo tempo vivemos no mundo de risco na qual somos agentes do "perder de si mesmo" e na criação de si, subjetivo-objetivada do ego, da vontade e da transcendência, superar limites que nos tragam prazeres enraizadas em nosso inconsciente, dessa maneira o mundo surge como uma situação sendo ele a historização:

"Este processo está rigorosamente ligado à 'situação do agente [...]: ele a define negativamente por seus limites e não seria possível apreendê-lo em si mesmo sem nós dessituar em relação a tudo a exterioridade transpassa a interioridade por toda parte]. CRD, p. 668.

O conflito mental como já apontado, é uma amalgama de impasses entre ID, ego e super ego, ou seja quando temos essas convulsões internas, nos vemos como indivíduos limitados na qual gera uma negatividade em uma visão mais ampla do todo, na qual privamos segundo Freud na satisfação dos nossos mais íntimos desejos O sonho é a satisfação de que o desejo se realize. A história do mundo implica na liberdade desde o nascimento, na condição humana em desenvolver-se de maneira autônoma fisicamente, moralmente, coletivamente e cognitivamente, e retornamos a fala de Sartre quando ele sugere que o homem está condenado a liberdade, na visão sartriana, o homem poderá satisfazer seus desejos e vontades de maneira nietzchieniana obtendo para si experiências prazerosas na qual ele consegue saciar seus desejos ou reprimi-la de maneira freudiana obtendo sofrimentos de modo depressivo e por vezes silenciosos na qual o indivíduo se vê de maneira negativa perante a sociedade colocando a culpabilidade ao seu redor pela não "oportunidade" de atender aos seus desejos, prazeres e expectativas como indivíduo, seguindo o pensamento sartriano, nascemos para satisfazer a grande necessidade que eu tinha de mim mesma, novamente temos uma análise subjetivo-objetivada do indivíduo inserido no mundo da liberdade e sua historização, na qual o subjetivo é a identificação do ser em si ao passo de atingir ao objetivo que é a realização de seus sonhos, logo alimentando seus prazeres mais íntimos ligados ao inconsciente.

A busca pelo prazer é um movimento constante para alcançar a transcendência do temporal para o atemporal, na qual o indivíduo é responsável por suas ações e escolhas objetivando seu progresso continuo, alimentando cada vez mais seu ego de maneira temporal e consequentemente 
atemporal, se identificando como um ser essencial na história que ele participa.

Quando procuramos entender o processo da construção do indivíduo em sua subjetividade, se faz necessário entender que o modo vivido não pode ser dissolvido apenas no saber, ou seja, é uma práxis te tentar entender a irredutibilidade e a especifidade do modo vivido, é uma análise concreta e complexa para que o transeunte não seja conhecido apenas no campo do saber e sim na valoração, na experiência vivida como todo.

Por outro lado é necessário analisar fatores exteriores como influenciadores do processo individual das escolhas, ações externas desencadeiam reações internas na qual pode impactar de maneira positiva ou negativa o comportamento da pessoa, novamente aqui retornamos as análises freudianas quando afirma que somos movidos pelos desejos, logo esses desejos são oriundos do sexo, na qual Freud toma como partida para seus estudos mais profundos, leia-se o complexo de Édipo quando o indivíduo mata seu pai, casa com sua mãe, gerando dentro dela uma vida, numa análise rápida vemos que ao final desse conto grego Édipo se cega por não conseguir ver a luz da verdade, dessa maneira tentando conectar-se ao seu mundo interior buscando respostas para algo que estava em sua frente, nesse processo Freud analisa o impeto do desejo de Édipo e a interferência dos fatores externos que levaram o indivíduo a escolher a realizar suas ações condicionadas a liberdade proporcionadas pelo mundo.

\section{O EXISTENCIALISMO EM LACAN E A SUA PRIMEIRA CLINICA}

Jaques Lacan dá inicio as suas análises filosóficas e psicanalítica partir de 1953, seus estudos sempre tem um retorno a Freud, dessa maneira sempre tentando fazer um paralelo entre os fundamentos do existencialismo e a psicanálise, na qual Lacan cria seu texto Função e campo da fala e da linguagem,

\footnotetext{
"O texto elaborado para um congresso realizado no Instituto de Psicologia da Universidade de Roma, o autor defende a necessidade de elucidação dos princípios norteadores da prática do analista na clínica, bem como chama a atenção de seus interlocutores para a importância de um diálogo tanto com a antropologia que estava sendo desenvolvida na segunda metade do século XX, quanto com a filosofia, na medida em que ambas poderiam trazer valiosas contribuições à psicanálise (LACAN, 1966, p. 240)."
}

Para Lacan tanto a antropologia como a filosofia acabam sendo eficientes para uma contribuição efetiva dentro da psicanálise, existe uma possibilidade de traçar uma corrente ou uma conexão entre a psicanálise de freudiana com a filosofia existencialista através de seu processo evoluiu e eclodiu no século XX, período esse de tantas transformações ou como já dizia o filósofo 
alemão Karl Jasper vivemos uma segunda era axial. Lacan acredita que análise do simbólico é uma deveria uma interferência direta para um estudo profundo, tema esse que na metade da década será o foco central dos estudos da psicanálise, basta olharmos novamente Freud para perceber que como pai da psicanálise, ele inicia seus estudos sobre o desejo simbólico do homem traçando suas pesquisas simbólicas ne estória de Édipo até as aflições humanas, também não menos importante o psicanalista Carl Gustav Jung, onde desenvolve sua famosa obra "O homem e seus símbolos", ou seja, Lacan utiliza novamente deste contexto para traçar e dar continuidade em suas observações através da simbiose filosófica e psicanalítica tendo como ponto central o imaginário, desejos e a existência do indivíduo. Lacan (1966, p. 252) afirma que a ideia de contato imediato com a realidade do sujeito presente na tradição fenomenológica - seria algo a ser descartado da experiência analítica, o que evidencia que não se trata, para o autor, de reduzir a psicanálise a uma doutrina filosófica, novamente vemos aqui em Lacan afirmação de excluir uma análise do fenômeno em si pelo sujeito vivido e inserido, mas buscar causas e motivos que levam o transeunte aquelas condições por ele experimentado,

\footnotetext{
“Trabalhar com vertentes do simbólico, tais como a palavra e a significação, Lacan se acerca, de fato, da perspectiva fenomenológico- existencial sem, entretanto, aderir a ela. Miller (2002, p. 20)."
}

Para Lacan compreender o sujeito numa análise simbólica não significa excluir toda sua vida e o empirismo por ele vivenciado, mas numa realidade subjetiva como já supracitado, se faz necessário tal entendimento para entender seus objetivos mais lúgubres reprimidos, quando se alcança a objetividade do indivíduo em si numa análise clara, inserimos a pessoa novamente dentro da sua significância com novos horizontes e novos experimentos que talvez não viveria se os estudos apontassem somente e unicamente em sua base fenomenológica, para além, Lacan acredita que reduziria a psicanálise para uma mera especulação filosófica sem algum tipo de efetividade, essa importante colocação, acrescentamos, então, que, em sua relação complexa com o existencialismo, Lacan, já nos primórdios de seu ensino, sustenta uma posição contrária às teses de Sartre e, nesse movimento, constitui sua primeira clínica, a qual, segundo Forbes (2012, p.66).

\section{AS DIFICULDADES DO EXISTENCIALISMO DE SARTRE PARA ANÁLiSES PSICALÍTICAS SEGUNDO LACAN E PONTY.}

O filósofo Maurice Merleau-Ponty (2009, p. 230) manifesta a dificuldade relacionada à utilização do termo «existencialismo», na medida em que, após 1945, ele teria sido vinculado, 
sobretudo, à filosofia produzida na França sob a influência de Sartre, o que, a seu ver, mascararia os seus antecedentes, ou melhor, a sua própria história. Como apontado pelo autor, Sartre parece trazer o existencialismo como algo apenas temporal, esquecendo por vezes que dentro do universo humano existe o atemporal (memória), inconsciente, pré-consciente e o consciente, existe toda uma estrutura interior para as suas ações e não apenas uma mera escolha da liberdade que o mundo proporciona ocasionando uma demanda de escolha livre para o sujeito, seguindo as linhas de Jean Beaufret (2000) considera, então, que o existencialismo seria um estilo de praticar a filosofia capaz de promover um abalo das certezas que o homem pode ter de si próprio. Esse abalo caracterizado por Jean é oriundo de radicalismo tratado na filosofia existencialista sartriana onde não deixa margens para uma análise prévia ou mais profundo no seu interior, dificultando o trabalho, ciência perante a essa estrutura complexa proposta pela escola existencialista.

Jean ainda continua na sua análise...desse ponto de vista, não há realidade humana constituída e pronta, já que o indivíduo será definido por um processo contínuo de construção de si mesmo. Trata-se, com efeito, de um movimento ininterrupto de vi-la ser, e portanto de nunca ser por inteiro. Nesse sentido, Beaufret (2000, p. 55). Recorremos a Freud quando fala da construção de si, o sujeito deve estar sempre na perda de si, para uma construção de si, onde dessa maneira ele acaba vendo-se como indivíduo ator da sua própria existência atuando constantemente na sua construção cognitiva dentro de uma liberdade social externa que leva-o a historização. Em suma, vemos a problemática instalada pela radicalidade do existencialismo quando se trata apenas estudos da femenologia deixando de lado a subjetividade-objetiva na sua construção continua da identificação, contrapondo a existência da essência. Ao consultarmos o dicionário de Gaffiot (1934/2000, p. 637), podemos entender que a existência vêm do verbo existere tranzendo seu significado de "sair", "movimentar", já que a palavra existência é uma nomenclatura desenvolvida tardiamente para denominar a existência, logo percebemos que o homem não pode viver sem sua coletividade existencial, mas que se faz necessário uma análise essencial do ser para ser objetivado, assim como lembra Husserl (1954, p. 344) sustenta que a consideração da dimensão concreta do mundo seria fundamental para a construção de uma reflexão capaz de colocar em destaque um «Eu que age e sofre» em um espaço, no qual a relação entre os seres implica que cada homem seja no outro e para o outro. Se olharmos novamente as análises filosóficas de Sartre, temos um outro contraponto, pois como radicalismo das escolhas do homem temporal, o sujeito como autor de suas escolhas, ele não poderá em nenhuma hipótese reclamar de seu destino, das consequências por ele acometido. Seria uma espécie de negação daquilo que sente? Daquilo que se arrepende? Daquilo que se sofre? Essas indagações na filosofia de Sartre não deixa margens para a culpabilidade e sim a glória do sujeito na superação das 
consequências na máxima frase por ele proferido: "Não importa o que o mundo fez de você, mas sim o que você fez do mundo, e o que fez de você”.

Se olharmos na perspectiva de Martin Heidegger, veremos que o autor aponta que a nossa existência têm apenas como base a existência não para ser analisada e sim vivida, ou seja ver para ver e não para atingir algo para a compreensão, a visão existencialista segundo ainda o autor, nos mostra que a vida "só é boa" dentro da coletividade, sem uma análise profunda do individual, Sartre se utiliza dessa premissa revelando:

"O modo de fazer filosofia «define o homem pela ação», já que seu destino está no que ele faz e não em uma suposta essência capaz de determinar sua subjetividade (SARTRE, 2011, p. 56).”

Novamente vemos Sartre colocando o existir como modo de ação no engajar da vida sem nenhuma prévia análise subjetiva, onde as consequências são movidas pelas as escolhas, acrescenta o filósofo francês: «o homem não é nada além que seu projeto, ele só existe na medida em que se realiza, ele não é nada além que o conjunto de seus atos, nada além que sua vida» (Ibid., p. 51), a intersubjetividade implica na liberdade humana, onde acaba esbarrando na limitação da sua livre escolha, então o autor logo entende que a pesquisa das causas temporais não pode ser enviadas para o campo atemporal, pois será sempre conflituoso dentro da realidade humana.

\section{LACAN E SUA VISÃO EXISTENCIALISTA}

No livro os Escritos de Lacan de 1966, compactua com à realidade heideggeriana, na qual a palavra é o norte da verdade humana, Lacan (2008, p.75) concebe a fala como uma «linguagem assumida por um sujeito». Em suma a fala segundo Lacan a palavra tem o poder de criar algo que não existia, quando professado ele passa a exitir nesse plano, o que existia antes da fala nos estudos de Lacan? A resposta é nada, pois a fala é projeção de algo inexistente analisando os desejos subjetivos do inconsciente para tornar-se realidade no mundo material.

Neste aspecto Lacan acredita que ação da psicanálise está ligada ação da fala, no seminário defendido por Lacan ele faz um paralelo entre a palavra vazia e a palavra concretizada estudando as diferentes palavras dentro do discurso das pessoas, em sua tese ele afirma que a palavra plena identifica a verdade dentro do sujeito e o que pode se manifestar em sua realidade, o lapso por exemplo, expressa uma intenção interior da pessoa, desejo esse de querer expressar algo na qual ela não consegue, para que a palavra adquira o valor verdadeiro é necessário identificar o simbolo como tal, acontece que, de acordo com Lacan (1953-1954/2009, p. 146) haveria uma face de resistência no 
nível da emissão da palavra, o que justificaria sua impossibilidade de «exprimir o ser do sujeito» por completo.

Por outro lado, Jacques-Alain Miller (1995, p.15), analisando o termo «desejo» em Lacan, explica que ele é utilizado «para designar algo que não é dito, a não ser cifrado, e isto indica a necessidade de situá-lo no campo da linguagem». Lacan (2008, p.63) concebe o sintoma como uma «fala amordaçada, inconsciente para o sujeito», e isso porque Lacan (Ibid., p. 61) crê que «a maioria das pessoas não fala, elas repetem». Ora, está claro que, quanto a isso, a referência só pode ser a noção de autenticidade em Heidegger. Lacan (1953-1954/2009, p. 338) defende que «o que fala no homem vai bem além da palavra até penetrar nos seus sonhos, seu ser». Nesse sentido, ele afirma, então, que o desejo recalcado «é o ser que espera se revelar» (Ibid., p. 351).

Como já supracitado neste artigo, Lacan faz uma comparação do desejo do homem intrínseco em relação ao desejo do outro, ao analisarmos esse contexto é possível ver que Lacan compartilha da oratória hegeliana, o desejo do outro para o outro, todavia, na dimensão humana, se o outro é importante por constituir a imagem que cada um tem de si, isto é, se «os desejos da criança passam inicialmente pelo outro especular», a aquisição da linguagem faz com que seja possível estabelecer com o outro um pacto (Ibid., p. 236). A criança é a imitação da sua existência subjetivada pelos seus familiares, ou seja, ela nasce dentro de um corpo subjetivo, buscando sua identificação de maneira objetiva através do progresso cognitivo, desenvolvendo em si a linguagem, quando se desenvolve essa linguagem, temos em mente que começa uma construção desejosa do existir em seu meio, novamente recordamos aquela frase freudiana em desconstruir o ser para o encontro de si mesmo como objetividade.

Voltando as ideas sartrianas, essa análise se torna incoerente, pois faz com que a liberdade do indivíduo acabe sendo aniquilado segundo a liberdade e a vontade do outro, excluindo qualquer tipo de ação do seu semelhante. Lacan acredita que o desejo, oriundo das paixões, não torna-o inútil, pois ele se torna base de análise,

\footnotetext{
“Assevera que, antes da linguagem, o desejo só existe no plano da relação imaginária, potencialmente destrutiva, e que, diante disso, a distinção dos «planos do simbólico, do imaginário e do real» seria essencial para se avançar na experiência analítica, Lacan (1953-1954/2009, p. 225).”
}

\section{DESEJOS E O EXISTIR}

Em 1955 Lacan apresentou um seminário sobre o EU, na qual ele admite uma dicotomia na qual a psicanálise tenta tratar, buscando dentro da subjetividade a objetividade do sujeito, Lacan afirma que Freud traz ao mundo um estudo inédito sobre o desejo dentro do inconsciente que se 
materializa no mundo, eis ai uma indagação: se o existencialismo se baseia na escolha, na ação e liberdade do sujeito, estudar a objetivação seria suficientemente para responder a existência do homem como o todo? E como explicar as mudanças comportamentais, seria algo apenas objetivo?

\begin{abstract}
"Destarte, ele sublinha que o desejo surge encarnado na palavra e, por essa razão, caberá ao analista criar as condições para que o sujeito possa «nomear, articular, fazer passar à existência esse desejo que, literalmente, encontra-se em uma dimensão aquém da existência, e que, por isso, insiste» em se fazer reconhecer (LACAN, 19541955/2001, p.313)."
\end{abstract}

Para Lacan a objetividade não é apenas objetivada dentro da existência, e sim um desejo subjetivado que se move acompanhado com os fatores exteriores, tornando-se simbolo no inconsciente pulsando desejos das mais variadas dentro do sujeito e nesse sentido Lacan apoia Freud quando afirma que o desejo do homem é tornar-se o autor de si próprio.

Outro ponto importante observado por Lacan dentro do existencialismo o simbolo que existe dentro do sujeito, é também fruto de traumas, ora essa que o transeunte vive dentro de uma coletividade e aquilo que ele vivencia, acaba obtendo experiencias traumáticas por vezes, segundo Freud quando o indivíduo obtém imagens traumáticas ela pode ficar instaladas no inconsciente, mas não significa que será esquecida, mas ela será o incomodo do sujeito, Lacan em contra partida afirma que a entrada do homem no campo do simbólico, implica no esquecimento das lembranças traumáticas, remetendo as lembranças simbólicas o tempo todo quando acessado, o sujeito é liberado dos laços, não somente da polidez, da cortesia, mas mesmo da coerência» (LACAN, 19531954/2009, p. 239) e ainda o importante, diz o autor em 13 de janeiro de 1954, é o que o sujeito reconstrói dos «eventos formadores da sua existência»(Ibid., p. 23). Ao analisarmos tais frases, entendemos que Lacan acaba se aproximando das teorias de Sartre, mas ainda sim, existe uma distância grande entre os dois pensadores, «todo o sistema humano em volta já nos define», e, desse ponto de vista, será na «conexão entre a dimensão imaginária e o sistema simbólico» que a história do sujeito irá se inscrever (Ibid., p. 208-209). Em suma, Lacan vê o existencialismo do homem antes do ser temporal, uma construção do ser atemporal, que acessa o imaginário platônico como uma espécie de "icloud", onde ali será e estará mantida todas as informações necessárias para a essencialidade do indivíduo dentro do espaço historiográfico na qual ele está inserido objetivamente. Como apontado já neste artigo, estudar o homem apenas pelas escolhas que faz é negar o lado sensitivo, emocional e cognitivo daquilo que ele sente, sofre e deseja, já que segundo S. Freud, o sofrimento é oriundo de um desejo occultado no inconsciente. 
"Ressalto que a única resposta plausível àquele que se dispõe a interrogar o domínio do simbólico só pode ser essa: «Come teu Dasein».Lacan (1966, p. 40)."

Buscar dentro do simbólico o conhecimento de si, deve ser um processo constante para retirar palavras taciturno, ou seja, uma identificação de si perante ao mundo, desejo é sempre o desejo de ser reconhecido com tal e não deixar cair numa inessencialidade apenas como projeções históricas das escolhas realizadas pelas ações deferidas, atitude do analista é de alguém que se mantém «permeável à fala autêntica do outro» (LACAN, 1966, p. 352). Para Lacan existe um mundo invisível na qual se faz necessária uma análise clinica, caso contrário, estaríamos fadados para Lacan numa espécie de declínio imaginário, abrindo portas para um mundo narcisista «experiência no limite da despersonalização». A isso, ele acrescenta: «É então que o contingente cai - o acidental, o traumatismo, os obstáculos da história - E é o ser que vem então a se constituir» (LACAN, 19531954/2009, p. 302, grifos do autor).

\section{EXISTENCIALISMO E PSICANÁLISE ANDAM JUNTOS EM DETERMINADOS MOMENTOS.}

"Nunca pois um homem se ofereceu tão alegremente em holocausto à sua doutrina", disse Lebrun (1993, p. 32)"

Poderíamos falar que Sartre seria tão irredutível assim como Lebrum ao tratar da psicanalise, pergunte para algum existencialista: "por que gosta de viver no perigo?” a resposta será: “porque escolher viver assim" ou "por que gosta de viver sempre no ócio e não têm dinheiro para sobreviver?" escutaremos: "porque trabalhar é chato e cansativo, prefiro mordomia ao meu modo", o tempo todo ouviremos que escolheram viver por suas escolhas "racionais" sem abrir margem de uma reflexão mais profícua, já os psicanalistas atribuirão essas ações ao inconsciente, vejamos:

"a psicanálise poderia dizer que o compromisso do sujeito com seu desejo (...), a aceitação da falta e do conflito como constitutivos de nossa condição, podem ter consequências éticas Maria Rita Kehl (2002, p. 31) "

Quando fazemos escolhas e respondemos "porque escolhi viver assim", entendemos que existe dentro do sujeito uma falta e ou uma negação de uma impulsão do nosso inconsciente ou na melhor das hipóteses, uma negação de si, quando tratamos da liberdade sartriana e dos processos psíquicos freudianos, apesar de inúmeras publicações entre os dois autores, poucos ainda se aventuram a entender como se dá esse processo sem prejudicar Sartre elou para Freud, quando alguns 
ainda tentam promover algum tipo de reflexão por exemplo, para não atingir aos dois estudos feitos, colocam na mesa uma abordagem superficial no conflito do "consciente e do inconsciente".

$\mathrm{Na}$ obra de Sartre em O ser e o nada, o autor ignora por completo qualquer relação do imaginário na influência do indivíduo, novamente aqui como já apontado, para que a liberdade aconteça de maneira significativa do homem para o homem, não poderá outro plano da liberdade à não ser o aqui e o agora,sem precisar colocar a liberdade em outro lugar, outro tempo, outras divindades e até mesmo na psique, não existe a imanência e transcendência interior e sim a busca constante da realização de seus desejos através do mundo temporal na qual o indivíduo está inserido. Mas para Freud é contraditória essa afirmação

\footnotetext{
"Não queremos apenas descrever e classificar os fenômenos, mas compreendê-los como sinais de um jogo de forças na psique, como manifestação de tendências dotadas de metas, que trabalham em consonância ou dissonância umas com as outras. Esforçamo-nos em obter uma concepção dinâmica dos fenômenos psíquicos. Nessa nossa concepção, os fenômenos percebidos devem ficar em segundo plano perante tendências apenas supostas. (Freud, 1916-1917/2014, p. 71)".
}

Numa entrevista de 1964 Sartre aponta que as análises freudianas tem uma bifurcação, refletindo que a psicanálise nada mais é que uma linguagem mitológica coisificante, onde a má-fé vive instalada na consciência das pessoas, algo que Freud jamais aceitaria, ainda para o autor, a pulsão, a emoção é uma finalidade dos fatos, característica exclusivamente humanas. A obra de Sartre O ser e o nada, aponta uma separação de dois opostos na qual quem poderá apenas julgar se está coerente ou não são os leitores freudianos, é bastante compreensível separar os polos, porém quando os sartrianos leem de maneira bastante atenta ao escrito do autor, acaba passando despercebidos os conceitos já descritos por Freud.

Sartre apesar de colocar a psicanálise como mera "mitologia", entende que existe uma escolha original, escolha essa na condição humana fazer aquilo que já foi feito, o homem condenado a liberdade, ainda sim faz coisas que são ligados ao nosso estado primitivo, ativamos nossos lados instintivos que nos acompanham desde a Revolução Cognitiva,

"Logo, também o passado, ou o que podemos chamar de "historialização" (Sartre, 1948/1989, p. 135)."

O que seria então o inconsciente para Sartre em sua análise? Seria o determinismo, passividade, positividade, negatividade, em poucas palavras vemos aqui que Sartre utiliza em outras palavras as concepções subjetivas ao modo objetivo do existencialismo, então logo entendemos que, toda a consciência "consciência de..." é conclusivo apontarmos que apesar das discrepâncias entre os 
dois pensadores, Sartre se aproxima nas conclusões de Freud para justificar o determinismo, também conscientemente acaba corroborando com as teses de Lacan sobre simbiose das palavras com o desejo, pois se a consciência é o nada (nadificação) e através das nossas escolhas criamos a causalidade, o autor pressupõe que existe uma simbologia transcendente para que os fatos aconteçam perante as nossas escolhas.

Por fim se o sujeito faz projeto, esperando um futuro porvir, logo cria uma causalidade criada da nadificação do consciente que nos remete a interação da psicanálise de Freud, de primeiro momento as elucidações de Sartre na obra O Ser eu nada nos remete algumas etapas especificas, de primeiro momento temos uma tese individualista do autor, mas ao decorrer da leitura vemos a segunda parte mais hermenêutica e flexível na busca da constante mudança do sujeito em seu existir, conclui Sartre: A dimensão do futuro não existe para a psicanálise. A realidade humana perde um de seus ek-stases e deve ser interpretada unicamente por uma regressão rumo ao passado a partir do presente. Ao mesmo tempo, as estruturas fundamentais do sujeito, que são significadas por seus atos, não são significadas para ele, mas para uma testemunha objetiva que usa métodos discursivos para explicar tais significações. Não se outorga ao sujeito qualquer compreensão pré-ontológica do sentido de seus atos. E isso é facilmente compreensível, pois, apesar de tudo, esses atos são apenas o efeito do passado - que, por princípio está fora de alcance - em vez de buscar inscrever seu objetivo no futuro. (Sartre, 1943/1981, p. 514)

\section{CONCLUSÃO}

Apesar das duas correntes teóricas se contraporem numa amalgama de aspectos, podemos entender que dentro da análise freudiana existe um desejo inconsciente que nos impulsiona para a existência, a desconstrução do ser é fundamental para as nossas descobertas, dos desejos mais profundos que carregamos no simbólico, como dirá Lacan a posteriore, dessa maneira divergindo com o existencialismo de Sartre onde o homem está condenado a liberdade e nada mais além. O existencialismo sartriano toma forma mais radical dentre outros filósofos existencialistas como vimos no decorrer desse artigo, ao lembrar de Martin Heidegger, Soren Kierkegaard, Arthur Schopenhauer, F. Nietzsche, vemos em Sartre que além do indivíduo ser autor de executar suas vontades, ele não pode atribuir suas ações, vitórias, derrotas para qualquer outro campo, sendo o "herói" para suportar todas as consequências e desafios do mundo a partir do momento que faz suas escolhas. Não existe para Sartre um desejo oculto no sujeito traçado, pois a partir do momento que as análises são realizadas no atemporal do transeunte, ele (o sujeito) acaba tendo sua liberdade reduzida á liberdade do outro. Vemos isso se manifestar em Lacan, quando o psicanalista afirma que a palavra é o simbolo 
norteador da criação do material dentro do temporal, ainda que exista uma linguagem taciturna, elas se manifestam de maneira falsa ou verdadeira, trazendo á tona a personalidade e o desejo instalado em cada pessoa, apenas dessa maneira será possível manifestar-se no campo real.

J. Lacan um seguidor de Freud acredita que a psicanálise pode contribuir na existência, essência e significação do ser, sem deixar que o peso da historização apague todo o significado do indivíduo no que tange o interior, para o psicanalista, não é possível analisar o homem apenas com olhar das suas ações e escolhas, pois o mundo real, temporal, é apenas um conjunto de fatores que o ser faz parte e nele está sujeito as mudanças comportamentais, seria superficial analisar o comportamento apenas pela "liberdade" que o mundo oferece ao sujeito, fazendo com que ele apenas seja mais um na história da humanidade, perdendo todo seu significado interior. Não é possível segundo ainda Lacan que as mudanças de comportamento possam ser respondidas somente e exclusivamente a existência em si, pois a pessoa sente dores, sente angústias, alegrias, adrenalinas, desejos e como explicar isso se não através de uma análise psicanalítica? Freud no inicio da década de XX, já tinha traçado um caminho através do estória do Édipo Rei para justificar a fonte dos nossos desejos, Carl Gustav Jung já tinha apontado o homem e seus símbolos, Lacan reforça mais uma vez simbologia dentro das palavras formadas e todas essas simbologias são simbioses dos desejos subjetivados em nossa inconsciência. Como supracitado durante o artigo enquanto o existencialismo olha apenas para objetivado, a psicanálise utiliza aquilo que Platão já falava no século IV a.c "quem deveria assumir o poder politico em Atenas não deveria ser os sofistas e sim os filósofos por entenderem tanto do atemporal como do temporal", fazendo uma anacronia aqui, para entender o ser humano dentro da sua significância e essência do existir, deve-se analisar por completo e não de maneira parcial elou superficial como os sartrianos apontam, porém é importante ressaltar que nos escritos do autor do O Ser e o Nada, Sartre admite que o indivíduo antes de obter uma liberdade de escolha, estamos presos a praticar as mesmas coisas desde os primórdios da humanidade, ainda que teórico acredite que a psicanálise deveria ser apenas uma linguagem mais simples e mitológico ao se transmitido as pessoas, ele corrobora com Freud que o homem tem uma consciência para realizar suas escolhas. Terminamos por concluir, que para além do discurso formulados pelas palavras ditas, há em toda a psicanálise a importância do "Não Dito", deixando assim claro, que nenhuma teoria é capaz de abarcar toda a subjetividade do comportamento humano, e que, a força da presença física em sua aparição e integralidade, traz à tona uma outra dimensão da linguagem, um discurso sem palavras que nos faz além de saber, entender, "sentir" o toque da alma de "outro" sem se misturar. Somos singulares mergulhados em plural. 


\section{AGRADECIMENTOS}

Certamente estes parágrafos não irão atender a todas as pessoas que fizeram parte dessa importante fase de minha vida. Portanto, desde já peço desculpas àquelas que não estão presentes entre essas palavras, mas elas podem estar certas que fazem parte do meu pensamento e de minha gratidão.

Agradeço ao meu orientador Prof. Dr. Alessandro Euzébio, pela sabedoria com que me guiou nesta trajetória.

A Secretaria do Curso, pela cooperação e pelo excelente atendimento.

Gostaria de deixar registrado também, o meu reconhecimento à minha família, pois acredito que sem o apoio deles seria muito difícil vencer esse desafio.

Agradeço a minha esposa por aturar meus surtos de estresse e loucura, afinal, estes foram momentos em que, mesmo de forma não tão consciente, aliviei o estresse, mesmo que de forma impulsiva, guiada pelo instinto animal.

Agradeço àqueles que chamo de Egr. Drac. Pelo suporte e manutenção de minha existência.

Enfim, a todos os que por algum motivo contribuíram para a realização desta pesquisa.

\section{REFERÊNCIAS}

SARTRE, Jean-Paul. O Existencialismo é um Humanismo. São Paulo: Abril Cultural, 1973, p. 12.

GAIO, Instituto. Introdução à psicanálise. Formação em Psicanálise Clínica.

CARLONI, Paola. A história e a constituição da Psicanálise: introdução aos principais conceitos freudianos para entender a subjetividade humana. 2011, p. 3.

FADIMAN, J.,Frager, R.Teorias da Personalidade. Harbra. 1980, Cap. 1.

GAIO, Instituto. Teoria Psicanalítica de Sigmund Freud I. Formação em Psicanálise Clínica

FREUD, Sigmund. Dois Verbetes de Enciclopédia. In: Edição Standard Brasileira das Obras Psicológicas Completas. Rio de Janeiro: Imago; 1976

Sartre, Freud e a oposição entre má-fé e inconsciente, São Paulo, Dezembro de 2016, disponível em: http://pepsic.bvsalud.org/scielo.php?script=sci_arttext\&pid=S1517-2430201600020000

O existencialismo filosófico e a primeira clínica de Jacques Lacan, 19/03/2017, Adriana de Albuquerque Gomes, disponível

file:///C:/Users/ueldi/OneDrive/\%C3\%81rea\%20de\%20Trabalho/lacan.pdf 